\title{
A VIOLÊNCIA SOCIAL E O GENOCÍDIO DA JUVENTUDE NEGRA DO BRASIL
}

\section{SOCIAL VIOLENCE AND THE GENOCIDE OF BLACK YOUTH IN BRAZIL}

\author{
Pedro Barbosa* \\ cosmocratico@gmail.com
}

RESUMO: No presente artigo, procuramos contribuir para o debate sobre a violência contra a juventude negra e pobre do Brasil, correlacionado sua condição social ao preconceito, ao racismo, à discriminação racial, à xenofobia e à intolerância correlata. Nesse contexto, a reflexão sobre essa violência, que segundo os dados estatísticos já se configura como forma de genocídio explícito contra esse segmento social, leva-nos a nos manifestarmos no sentido de apontar algumas causas que, em nosso entender, ilustram esse quadro perverso e caótico contra a população que denominamos de "afro-brasileira" (pretos e pardos) ou juventude negra e pobre (tratamento que damos às vítimas dessa tragédia social). Como resultados esperados, objetivamos ampliar esse debate no espaço acadêmico, apontando algumas hipóteses sobre as causas da violência e do genocídio contra a juventude negra e pobre e, simultaneamente, apontamos alguns caminhos encontrados para a superação dessa problemática.

PALAVRAS-CHAVE: Juventude negra e pobre, Educação, Desemprego, Violência e genocídio.

ABSTRACT: In this article we aim to contribute to the debate on violence against black and poor youth in Brazil by correlating their social condition along with prejudice, racism, racial discrimination, xenophobia and related intolerance. Likewise, giving thought to this violence already depicts a form of explicit genocide against this very social segment according to statistical data and it leads us to stand out as a researcher in the academic field in order to reveal some causes that, based on our understanding, portrays this perverse and chaotic picture of the so-called "afro-brazilian" (blacks and browns) population or black and poor youth (this is how we call the victims of this social tragedy). As expected results, we intend to broaden this debate in academic field by pointing out some hypotheses about the roots of violence and genocide against black and poor youth, and at the same time, we will indicate ways found to overcome this problem.

KEYWORDS: Black and poor youth, Education, Unemployment, Violence and Genocide.

\section{Introdução}

A reflexão sobre a violência contra a juventude negra e pobre brasileira em nosso cotidiano perpassa, necessariamente, por uma abordagem antropológica e sociológica sobre em quais contextos sociais esse segmento étnico-racial se encontra em nossa sociedade, principalmente quando nos propomos a questionar como esse segmento social é imaginado pela elite branca detentora da hegemonia econômica, cultural, política e ideológica, bem

\footnotetext{
* Professor Adjunto do Curso de História da Universidade Federal de Jataí. Atua nas áreas de pesquisas em História e Cultura Afro-Brasileira, Africana e Indígena, Educação para as Relações Étnico-Raciais e Educação em Direitos Humanos. Possui Graduação em Ciências Sociais pela Universidade Federal de Uberlândia/UFU (2008), Mestrado em Ciências Sociais pela Universidade Federal do Rio Grande do Norte/UFRN (2011) e Doutorado em Ciências Sociais pela Universidade Estadual Paulista Júlio de Mesquita Filho/UNESP (2014). É Pós-Doutor em Antropologia Social no Programa de Pós-Graduação em Antropologia Social (PPGAS) da Universidade Federal de Goiás/UFG (2020).
} 
como em quais circunstâncias sociais estão inseridos e que futuro esses jovens podem ter e imaginam, além do que podem fazer para alcançá-lo.

A despeito de todas as crenças, sabemos que, no Brasil, a população denominada "afro-brasileira" (pretos e pardos), de acordo com as últimas estatísticas etnográficas feitas pelo Instituto Brasileiro de Geografia e Estatística (IBGE), em 31/07/2020, ultrapassou mais de 54\% da população. Além disso, as projeções futuras garantem que a tendência será de um crescimento ainda maior, mesmo com a persistência da violência e com o genocídio histórico praticados pelas forças opressivas e repressivas do Estado, desde o período da sociedade escravista, contra a juventude negra e pobre.

$\mathrm{Na}$ atualidade, algumas pesquisas apontam que os números da violência contra a população negra e pobre (WAISELFISZ, 2016) foram tão alarmantes que causaram incômodos e preocupações quanto aos direitos humanos até nos fóruns da Organização dos Estados Americanos (OEA), com sede em Washington, Estados Unidos. Em uma pesquisa sobre o mapa da violência organizada pela Faculdade Latino-americana de Ciências Sociais (Flacso), com base em óbitos causados principalmente por armas de fogo e suas variáveis, os resultados numéricos apontam que a juventude negra e pobre foi a maior vítima dos homicídios praticados em nosso País. Segundo a Anistia Internacional, dos 56 mil homicídios ocorridos por ano no Brasil, mais da metade são entre os jovens. Dentre esse segmento social, dos que morrem, 77\% são negros (CERQUEIRA et al., 2016, p. 54-60).

Ainda de acordo com a publicação intitulada Mapa da Violência 2016, essa violência vem aumentando cada vez mais no País. A taxa de homicídios contra negros e negras, por exemplo, aumentou 9,9\% entre 2003 e 2014, passando de 24,9\% para 27,4\%. Outro aspecto que chama muito a atenção em relação à vitimização da população negra e pobre do Brasil é que, em 2003, os óbitos, que somavam 71,7\%, duplicaram durante o ano de 2014, alcançando a somatória de 158,9\%, significando uma margem de mortes de 2,6 vezes mais negros/as que brancos/as vitimados por armas de fogo (WAISELFISZ, 2016, p. 54-60). 
Portanto, diante dessa calamidade pública em que vivemos em pleno estado de direito, mesmo depois de quase três décadas da promulgação da Constituição de 1988, apelidada de "Constituição Cidadã", ${ }_{1}^{1}$ pretendemos refletir e contribuir para esse debate.

Juventude negra: antecedentes históricos das imagens e os imaginários produzidos $e$ reproduzidos pela elite branca

Historicamente, a juventude negra e pobre brasileira é imaginada pela elite branca, detentora da hegemonia econômica, cultural, política e ideológica, como o resultado de um passado sombrio de mais de três séculos de escravidão. Muitos estudiosos das áreas de sociologia sobre a temática das relações raciais no País (FERNANDES, 1978; HASENBALG, 2005; JACCOUD et al., 2009; RIBEIRO, 2006; entre outros) entram em consenso ao avaliarem que todas as condições sociais (educação, desemprego, moradia, marginalização, etc.) de precarização de negros/as são herança da sociedade escravocrata.

Na mesma linha de raciocínio, pesquisadores/as de antropologia (GOMES, 2005; GONZÁLEZ, 1979; HOFBAUER, 2003; MUNANGA, 1986; SANSONE; PINHO, 2008; SCHWARCZ, 1993) também entendem que o preconceito, o racismo e a discriminação racial são construções sociais históricas decorrentes da sociedade escravista. Nesse contexto, preconizam que a temática envolvendo as diferenças, numa perspectiva de pensar e respeitar o outro étnico-racialmente nascido, construído e desenvolvido como resultado da produção de identidades de cunho étnico-racial, sempre foi importante na antropologia, principalmente quando olhamos para o Brasil (SANSONE; PINHO, 2008).

A partir das abordagens da literatura dos autores e autoras citados, tomamos conhecimento de que, durante a segunda metade do século XIX, com os debates em torno da abolição e das especificidades étnicas e políticas do Brasil, a questão das relações raciais se transformou no principal referencial temático dos estudos de Antropologia e Sociologia.

A socióloga Luciana de Barros Jaccoud e colegas observam que, ainda organizado politicamente sob a forma de Império - numa certa linha de continuidade com a herança da tradição portuguesa -, havia entre as elites brancas do País uma busca de identificação do Brasil como uma nação europeia por origem, seja na cultura, seja na organização político-

\footnotetext{
${ }^{1}$ A Constituição de 1988, a sétima da história brasileira, foi batizada de "Constituição Cidadã" pelo presidente da Assembleia nacional Constituinte (1987-1988), o deputado Ulysses Guimarães (1916-1992), porque tornou-se a primeira a permitir a incorporação de emendas populares.
} 
educacional, como se identificação fosse vocação de destino. Em boa parte da literatura romântica nacionalista, a mestiçagem e as possíveis variedades étnicas aparecem idealizadas, alocadas em valores e narrativas europeizantes:

[...] ainda que a elite colonial brasileira não tenha organizado um sistema de discriminação legal ou uma ideologia racista que justificasse as diferentes posições dos grupos raciais, esta compartilhava um conjunto de estereótipos negativos em relação ao negro que amparava sua visão hierárquica da sociedade. Neste contexto, o elemento branco era dotado de uma positividade que se acentuava quanto mais próximo estivesse da cultura europeia. (JACCOUD et al., 2009, p. 20).

Por consequência, nas áreas de estudo de ciências humanas, principalmente nas com foco em estudos antropológicos, é de conhecimento geral que os valores humanos de origem europeia se desenvolveram a partir do princípio de eugenia, ${ }^{2}$ desdobrando-se no racialismo ou "racismo científico" (SCHWARCZ, 1993). A partir desse pressuposto de "racismo científico", a concepção eugenista ("boa geração") foi desenvolvida pelo antropólogo inglês Francis Galton (1822-1911). ${ }^{3}$ A teoria da eugenia prioriza, nas ciências, o melhoramento das qualidades inatas de uma pressuposta raça em favor da evolução da humanidade. Nesse sentido, consideram que os cérebros de uma "raça-pátria-nação" se encontravam, sobretudo, em suas elites (pessoas da raça branca), e aí se deveriam concentrar a atenção e os esforços para o aprimoramento. Seria estatisticamente "mais proveitoso" investir nessas elites e promover o "melhor estoque do que favorecer o pior". A teoria da eugenia, a partir de seu criador, procurou demonstrar que as características humanas (inclusive as intelectuais, culturais e morais) decorriam da hereditariedade mais que da própria história (GALTON, 1865).

A partir da lógica dessa teoria eugenista, a única raça capaz de possuir status de sujeito social seria a branca. Na concepção dos adeptos dessa teoria, os genocídios cometidos pelos colonizadores europeus durante os processos de exploração e ocupação das colônias africanas e americanas seriam mais uma busca do apuramento das raças humanas no sentido de justificar o processo de civilização.

\footnotetext{
2 Eugenia tornou-se um termo criado por Francis Galton (1822-1911), que a definiu como o estudo dos agentes sob controle social, que podem melhorar ou empobrecer as qualidades raciais das futuras gerações, seja física, seja mentalmente.

${ }^{3}$ Antropologista, meteorologista, matemático e estatístico inglês nascido próximo a Sparkbrook, perto de Birmingham, criador do termo eugenia e descobridor da individualidade das impressões digitais (1885), mais conhecido pelos seus estudos de hereditariedade e inteligência humana.
} 
No decorrer das primeiras décadas do século XX, a teoria eugenista foi evoluindo para um caráter geneticista. $\mathrm{O}$ evolucionismo social procurou mais na origem genética e menos nas alterações genéticas herdadas as explicações e justificativas para a eugenia e a disgenia. A pureza da origem, ou a falta dela, ganhou status explicativo da superioridade e da inferioridade humana e da nação, sobretudo, as teorias sustentadas pelo darwinismo social. ${ }^{4}$

Nesse sentido, prevalecia, no Brasil, a política de estabelecer as diferenças entre a parcela civilizada, aristocrática e superior da população - identificada à raça branca - e a parcela atrasada, não civilizada e inferior - identificada aos demais segmentos étnicos. Por conseguinte, negros e indígenas ${ }^{5}$ passaram a ser considerados seres inferiores de acordo com as concepções raciais impostas pelos determinismos raciais ${ }^{6}$ adotados principalmente por Sílvio Romero (1851-1914), Euclides da Cunha (1866-1909) e Oliveira Viana (1883-1951), considerados os precursores das Ciências Sociais no Brasil.

$\mathrm{Na}$ teoria desenvolvida pelos determinismos raciais europeus e abraçada pelos autores brasileiros supracitados, encontramos como tese principal a ideia de que as condições raciais e climáticas de uma sociedade são decisivas para seu desenvolvimento. Assim, segundo essa teoria, como a realidade brasileira foi marcada pela existência de uma população composta por negros, índios e brancos/mestiços, caberia a esse último a tarefa de purificar a sociedade rumo ao progresso civilizatório.

No Brasil, a partir da importação e interpretação dessas ideias, alguns intelectuais defenderam com entusiasmo o branqueamento (HOFBAUER, 2003) ${ }^{7}$ da população, com o

\footnotetext{
${ }^{4}$ O Darwinismo Social, juntamente com a antropologia e a etnografia do século XIX, ajudou a construir a ideia de "missão civilizatória" das potências imperiais. Desse modo, o chamado neoimperialismo das últimas décadas do século XIX trazia consigo a noção de que havia um "fardo do homem branco" de levar o progresso e a civilização aos povos "primitivos" e "atrasados" (entenda-se, negros e indígenas).

${ }^{5}$ Seguindo a mesma linha do darwinismo racial encontra-se a obra de José Arthur, o conde Gobineau, Ensaio sobre a desigualdade da raça humana (Essai sur l'inégalité des races humaines), de 1853-1855, considerada a bíblia do racismo moderno.

${ }^{6} \mathrm{Na}$ teoria fundamentada no determinismo racial, a raça determina o desenvolvimento civilizacional. Nessa linha de pensamentos, as raças devem se manter puras. A raça negra é considerada inferior e a mistura entre as raças gera degeneração.

${ }^{7}$ Andreas Hofbauer - Se entendermos o branqueamento numa perspectiva antropológica, ou seja, como uma construção simbólica, a ideia de transformar corpos negros em brancos é apenas um aspecto de um ideário muito mais profundo e abrangente. A ideologia do branqueamento costuma ser associada, no Brasil, aos projetos imigracionistas que, na virada do século XIX para o XX, trariam milhares de europeus brancos ao País. A ideia da imigração europeia, que já fazia parte dos primeiros projetos abolicionistas (no início do século XIX), visava não apenas modernizar a produção. Assim, em 1821, o médico e filósofo Francisco Soares Franco apresentou um projeto no qual propôs que o lento processo de emancipação deveria ser acompanhado por uma política
} 
objetivo de corrigir o atraso do País. Essa ideia serviu para justificar, naquele momento de intenso fluxo migratório de europeus e asiáticos em direção às Américas, ${ }^{8}$ a importação de mão de obra, desconsiderando o imenso contingente de trabalhadores disponíveis, formado pelos escravizados. A ideologia do branqueamento fortaleceu a exclusão social dos negros, impediu o surgimento de uma consciência mais resistente entre esse segmento e contribuiu para instituir, no Brasil, o mito da democracia racial.

Assim, a partir dessa concepção determinista racial, Silvio Romero (1906) acreditava que a raça branca se imporia aos não brancos, com o passar do tempo, no território brasileiro, impondo sua supremacia civilizatória. Ou seja, o País constituir-se-ia como um povo de raça branca capaz, de acordo com as concepções raciais europeias e estadunidenses, de se civilizar. Portanto, afirma esse autor (1906, p. 51) que

[a] formação da nacionalidade significaria, necessariamente, a vitória do branco sobre os outros dois elementos que a compuseram originariamente. Esse branco/mestiço superior venceria os fracos (negros e indígenas) e estaria adaptado ao meio. Assim se constitui e se (re) atualiza o mito fundador do povo brasileiro assentado nas três raças formadoras originais.

Inoportunamente, o determinismo racial também é retomado por Euclides da Cunha (2001) na obra Os sertões. No contexto de seu trabalho, existe uma relação entre o clima e a raça acentuadamente determinista:

A mistura de raças mui diversas é, na maioria dos casos, prejudicial. Ante as conclusões do evolucionismo, ainda quando reaja sobre o produto do influxo de uma raça superior, despontam vivíssimos estigmas da inferior. A mestiçagem extremada é um retrocesso. $O$ indo-europeu, o negro e o brasílio-guarani ou o tapuia exprimem estádios evolutivos que se fronteiam, e o cruzamento, sobre obliterar as qualidades preeminentes do primeiro, é estimulante à revivescência dos atributos primitivos dos últimos. De sorte que o mestiço - traço de união entre as raças, breve existência individual em que se comprimem esforços seculares - é, quase sempre, um desequilibrado. [...] menos que um intermediário, é um decaído, sem a energia física dos ascendentes selvagens, sem a altitude intelectual dos ancestrais superiores. Contrastando com a fecundidade que acaso possua, revela às vezes, mas frágeis, irrequietos, inconstantes, deslumbrando um momento e

imigracionista, a qual deveria ter como objetivo a homogeneização da nação, isto é, a transformação da raça negra em raça branca. Esse processo - segundo ele - poderia ser efetuado num prazo de três gerações. Noventa anos depois, quando o fluxo imigratório estava em pleno andamento, o antropólogo João Baptista Lacerda repetiria esse prognóstico, num discurso muito citado, no Congresso Universal das Raças, em Londres (1911), afirmando que a imigração europeia e a seleção sexual (preferência por casamentos com brancos) fariam com que a raça negra fosse extinta dentro de um prazo de cem anos (HOFBAUER, 2003).

${ }^{8}$ O historiador José Murilo de Carvalho, em Os três povos da República, estima que, entre 1850 e 1914 , aproximadamente 30 milhões de pessoas emigraram da Europa para a América, principalmente para os Estados Unidos, Brasil e países da Bacia do Prata. 
extinguindo-se prestes, esmagados pela fatalidade das leis biológicas, chamados ao plano inferior da raça menos favorecida [...] E quando avulta [...] capaz das grandes generalizações ou de associar as mais complexas relações abstratas, todo esse vigor mental repousa [...] sobre uma moralidade rudimentar, em que se presente o automatismo impulsivo das raças inferiores (CUNHA, 2001, p. 199-200).

Por conseguinte, a ideia do determinismo racial característico dos racistas europeus permaneceu influenciando autores brasileiros além dos já citados. Oliveira Vianna (1987), como os demais autores citados, também foi influenciado pelo racismo científico do século $\mathrm{XIX}$. Assim como seus antecessores, considerava que o cruzamento das raças diferentes, a mestiçagem, não era, sob nenhuma hipótese, aceitável, sendo perniciosa e negativa,

[...] porque também é lei antropológica que os mestiços herdem com mais frequência os vícios que as qualidades dos seus ancestrais. Os mestiços desta espécie são espantosos na sua desordem moral, na impulsividade de seus instintos, na instabilidade de seu caráter. $O$ sangue disgênico, que lhes corre nas veias, atua neles como a força da gravidade sobre os corpos soltos no espaço: os atrai para baixo com velocidade crescente. À medida que se sucedem as gerações. Os vadios congênitos e incorrigíveis das nossas aldeias, os grandes empreiteiros de arruaças e motins das nossas cidades são os espécimes desse grupo (VIANNA, 1987, p. 104).

Desse modo, a partir das concepções deterministas raciais dos estudos nas áreas de ciências humanas, sobretudo de antropologia, psicologia e sociologia realizadas por esses autores, assistimos, no decorrer do século XIX e nas primeiras décadas do XX, aos pressupostos ideológicos que produziram e reproduziram preconceito, racismo, discriminação racial, xenofobia e todas as formas de intolerância correlatas que ainda povoam o imaginário social brasileiro em pleno século XXI contra a população negra, principalmente quando se trata da juventude negra e pobre que são, nas estatísticas, os maiores índices de vítimas em violências.

Em quais circunstâncias materiais a juventude negra está inserida?

A partir de uma abordagem crítica da literatura das concepções deterministas raciais realizadas por alguns autores tanto da antropologia como da sociologia, podemos auferir que as teorias racistas desenvolvidas no decorrer do século XIX e na primeira metade do século XX macularam a população negra e pobre no Brasil e continuam repercutindo como lógica de segregação racial em pleno século XXI. 
Aprofundando-nos em algumas análises incontinentes sobre o processo de abolição da sociedade escravista, percebemos indícios segregacionistas desenvolvidos pela elite branca, que manifestava ideais progressistas e, simultaneamente, segregacionistas. 0 antropólogo Andreas Hofbauer (2003, p. 79) salienta que,

[c] hama a atenção o fato de que todos os projetos políticos que visavam abolir a escravidão vinculavam a implementação da "abolição" à ideia da importação de mão-de-obra europeia (= "branca"). Baseados numa concepção já "mais naturalizada" de "negro" e "branco", os "espíritos progressistas" da época estavam convencidos de que a "mão de-obra branca" seria mais produtiva que a "mão-de-obra negra". "Branco" já não simbolizava mais exclusivamente valores morais religiosos nem só o status de liberdade: agora a cor branca seria também projetada na ideia do progresso.

Fazendo uma leitura racional da linha do tempo no passado e correlacionando com nosso presente, podemos compreender que essa construção ideológica do negro como ser da transgressão e do branco como o ser da liberdade e do progresso não poderia reservar para a população negra e pobre outra cosmovisão social que não fosse a de marginalização.

A antropóloga e ativista do movimento negro Leila González (1935-1994) observou que, a partir do momento em que analisamos as reais condições sociais da juventude negra e pobre no Brasil, nos deparamos, historicamente, com sua insolúvel marginalidade:

Se colocamos a questão da funcionalidade da superpopulação relativa, constatamos que, no caso brasileiro, grande parte dela se torna supérflua e se constitui em uma massa marginalizada em face do processo hegemônico. Claro está que todas as questões relativas ao desemprego e ao subemprego incidem justamente sobre essa população. E, "coincidentemente", os mais baixos níveis de participação na força de trabalho pertencem à população negra brasileira. (GONZÁLEZ, 1979).

Em 1950, encarregado pelo Unesco de fazer um estudo sobre os negros no Brasil, o sociólogo Florestan Fernandes passou a pesquisar a relação raça e classe em São Paulo. Fundamentado em dados empíricos, esse autor se lançou ao confronto da ideia de que no País não existia uma "democracia racial". Na verdade, para esse estudioso, as desigualdades raciais e sociais predominaram no Brasil mesmo após a abolição, como resultado de duas heranças perversas do regime escravocrata que impediram os negros de competir com os imigrantes: o racismo e a incapacidade dos negros de se integrarem à ordem social competitiva.

Perdendo sua importância privilegiada como mão de obra exclusiva, ele (o negro) perdeu todo o interesse que possuíra para as camadas dominantes. As nossas observações evidenciaram duas tendências globais. Primeira uma 
que se associa à proletarização. As parcelas da "população de cor" que lograram classificar-se socialmente, em sua quase totalidade, cabem nessa categoria. Segundo, outra que se vincula à ascensão do negro e do mulato a ocupações ou profissões cujo nível de renda assegura um padrão de vida e prestígio social mais ou menos característicos das classes médias da sociedade inclusiva. A nossa experiência demonstrou que esta tendência afeta um número muito reduzido de pessoas. Além disso, existem casos esporádicos de 'indivíduos de cor' e de 'famílias negras' de fato pertencentes aos estratos superiores do sistema. (FERNANDES, 1978, p. 156-157).

Para Fernandes (1978), o dilema racial da sociedade brasileira está relacionado ao fato de que a abolição da escravatura no Brasil ocorreu de forma precipitada, sem assegurar aos negros livres uma verdadeira integração na sociedade dos brancos. Excluídos do mercado de trabalho e sem formação profissional e experiência no mercado de trabalho livre (competitivo), os antigos escravos necessariamente ficariam à margem dos processos de inclusão e modernização em marcha, dos quais somente os imigrantes (japoneses, italianos, alemães, poloneses, etc.) passariam a se beneficiar em longo prazo.

No final dos anos 1970, o sociólogo Carlos Hasenbalg, ao publicar o livro Discriminação e desigualdades raciais no Brasil (1979), nota que ser branco e pobre no Brasil nunca será o mesmo que ser negro e pobre, porque apresentar aos negros pobres as mesmas políticas públicas de igualdade social propiciadas aos brancos significa ignorar sua condição histórica. Para esse autor (2005, p. 116-120),

[...] Desde a abolição, a população negra nas antigas sociedades escravistas das Américas tem estado na retaguarda do capitalismo industrial. Durante várias décadas após a abolição, os negros ficaram concentrados nas regiões agrícolas mais atrasadas como parceiros, pequenos arrendatários, camponeses e moradores. [...] Com a abolição do escravismo, o racismo, como construção ideológica e conjunto de práticas mais ou menos articuladas, foi preservado e em alguns casos até mesmo reforçado.

Desse modo, a tese central defendida por Hasenbalg é a de que a exploração de classe e a opressão racial se articularam como mecanismos de exploração do povo negro, alijando-o de bens materiais e simbólicos. Partindo de um dualismo que lhe é próprio, afirma que os negros foram, ao longo do tempo, explorados economicamente e essa exploração foi praticada por classes ou frações de classes dominantes brancas. Para ele, a abertura da estrutura social em direção à mobilidade está diretamente ligada à cor da pele e, nesse âmbito, a raça constitui um critério seletivo no acesso à educação e ao trabalho.

Precisamente, outro trabalho sociológico que merece atenção sobre como a questão racial é fator determinante da desigualdade social no Brasil é Classe, raça e mobilidade social 
no Brasil (2006), de Carlos Antônio Costa Ribeiro. O autor analisa que as condições de igualdade e oportunidades para mobilidade social no Brasil são condicionadas mais pela raça do que pela classe social. Em seu trabalho é possível perceber uma fonte analítica baseada em dados quantitativos que mostra, com detalhes, a discrepância da desigualdade racial existente no Brasil. Para Ribeiro (2006, p. 855-856),

[n]a sociedade contemporânea, uma das mais importantes vias de mobilidade social é a educação formal. [...] Ser filho de médico ou juiz não qualifica ninguém como médico ou juiz, o que qualifica são as escolas de medicina e de direito. No entanto, é fato amplamente discutido que filhos de profissionais qualificados de alcançarem níveis educacionais mais altos [...]. Brancos também têm mais chances de sucesso do que não brancos, mas o peso da classe de origem é maior do que o da raça. Em outras palavras, podemos dizer que há mais desigualdades de oportunidades educacionais em termos de classe do que de raça. No entanto, nas últimas transições, a raça passa a ter um efeito semelhante ao da classe, ou seja, as chances de entrar e completar a universidade são desiguais em termos raciais e de classe.

Assim, as circunstâncias educacionais em que está inserida a população negra e pobre no Brasil acentua grandes disparidades. Quando abordamos o tema juventude negra no quesito educação, percebemos que suas condições estão mescladas em oportunidades e desafios muitas vezes definidores de perspectivas e possibilidades. As experiências de escolaridade revelam que a juventude negra aparece em sua precariedade, expressão da crise da sociedade capitalista que sempre atingiu a juventude negra pobre (HENRIQUES, 2001). De acordo esse estudioso, no Brasil,

[...] a escolaridade média de um jovem negro com 25 anos de idade gira em torno de 6,1 anos de estudo; um jovem branco da mesma idade tem cerca de 8,4 anos de estudo. O diferencial de 2,3 anos de estudos entre jovens brancos e negros de 25 anos de idade é a mesma observada entre os pais desses jovens. E, de forma assustadoramente natural, 2,3 anos é a diferença entre os avós desses jovens. Além de elevado o padrão de discriminação racial expresso pelo diferencial na escolaridade entre brancos e negros, mantém-se perversamente estável entre as gerações.

Ao cruzar dados recentes sobre a condição econômica e educacional e o acesso ao ensino superior da população negra no Brasil, mesmo após a implementação da lei de cotas raciais, também percebemos que a juventude negra pobre continua no ponto mais baixo da escala socioeconômica do Brasil, pois 64\% deles não completam a educação básica. 0 impacto dessa situação social é que muitos vivem às margens da sociedade e a juventude negra pobre ainda sofre com o acesso limitado à educação de qualidade no ensino superior, ou seja, não 
conseguem entrar nas universidades públicas, que são infinitamente melhores que as de ensino privado de cursos superiores.

Nessa linha de raciocínio, da mesma forma recordamos que Munanga (2001, p. 34) estimava dever existir instrumentos paralelos às cotas raciais para diminuir as desigualdades. Isso porque o Brasil sempre teve um menosprezo pela qualidade da educação básica pública e atenção apenas para o debate na esfera do acesso ao ensino superior: "a cota obrigatória se confirma, pela experiência vivida pelos países que a praticaram, como uma garantia de acesso, e de permanência neles, aos espaços e setores da sociedade até hoje majoritariamente reservados à 'casta' branca da sociedade".

Portanto, mesmo sendo favoráveis e reconhecendo que as cotas raciais se configuram como ações afirmativas no Brasil, não obstante entendemos que ela é apenas paliativa, pois fica muito longe de contemplar a maioria de negros/as em função das grandes discrepâncias históricas de acesso da juventude negra pobre às universidades públicas.

Ao conjecturar esses fatos é possível apontar que uma das justificações concretas dessa ocorrência sejam as condições históricas em que se situa a juventude negra nas escolas públicas, sobretudo nos processos de concorrência para alcançar o ensino médio no tempo ideal de sua realização, que normalmente ocorre entre os 15 e os 17 anos. Segundo dados apresentados no Relatório Anual das Desigualdades Raciais no Brasil (PAIXÃO et al., 2010), trabalhados a partir dos microdados fornecidos pelo IBGE, no ano de 2008 , a taxa líquida de matrícula no ensino médio para jovens negros era de $42,2 \%$ e, para brancos, de $61 \%$.

No decorrer dos anos subsequentes a 2010, embora reconheçamos que as diferenças de escolaridade entre negros e brancos tenham diminuído consideravelmente, também entendemos que ela ainda é substancial no atendimento adequado entre a idade ideal e a etapa da educação básica cursada. Isso implica dizer que de cada 100 estudantes negros/as que concluem o ensino médio, mais da metade estará fora da idade ideal no momento da conclusão: 17 anos.

Portanto, se conclui que a inadequação dos estudantes negros/as pobres ao sistema educacional brasileiro progride enquanto se avança na hierarquia do próprio sistema. Ao longo dos anos, são os estudantes pertencentes à juventude negra os mais prejudicados, pois, ao chegarem ao ensino médio, apenas $26,2 \%$ deles estão matriculados na série ideal. 
No Brasil, negros são $75 \%$ entre os mais pobres; os brancos, $70 \%$ entre os mais ricos. Um estudo feito pelo Instituto Brasileiro de Geografia e Estatística (IBGE) em 2019, intitulado Desigualdades Sociais por Cor ou Raça no Brasil e divulgado em 13 de novembro de 2019, aponta que os negros possuem os piores indicadores de renda e são as principais vítimas de homicídio no Brasil. Por outro lado, pela primeira vez a população negra é maioria no ensino superior público. Trabalhadores brancos possuem, em média, uma renda quase $74 \%$ superior à de pretos e pardos, uma diferença que vem se mantendo praticamente estável nos últimos anos (IBGE, 2019).

Diante dessas conjecturas, os números do Mapa da Violência de 2016 se apresentaram mais dramáticos contra esse segmento social. Segundo esses dados, durante um período de 30 anos as mortes por armas de fogo, por exemplo, cresceram $346 \%$. Mas nos casos dos jovens, esse crescimento foi de $414 \%$. Aqui também a juventude negra aparece mais exposta, com $133 \%$ a mais de mortes do que brancos.

Entrementes, na cosmovisão da sociedade brasileira, existe um mito de que os índices de violência são causados pelos denominados menores infratores. Ou seja, na ausência de informações com análises aprofundadas com base em metodologias antropológicas e sociológicas, a maioria da população brasileira acaba sendo influenciada pelos exercícios ideológicos da grande mídia conservadora, que propaga diuturnamente esse mito. Nesse sentido, a sociedade, de modo geral, não consegue perceber a verdade dos fatos e que a juventude negra e pobre é a maior vítima da violência de uma sociedade que a exclui dos processos de acessos a uma boa educação pública de qualidade, relegando-a ao desemprego e ao subemprego nas sociedades subdividas em raças e classes. Repetem, insistentemente, o que ouvem e assistem na mídia conservadora em seus programas policiais de índoles sensacionalistas, justificando, cegamente, a violência contra essa juventude, banalizando as ações dos denominados crimes de menores infratores.

Na contramão desse mito, existem dados estatísticos com fundamentação científica. Dentre eles, chama mais a atenção um já bastante divulgado pela Unicef Brasil, que mostra que, dos 21 milhões de adolescentes do Brasil, menos de um por cento (0,013\%) cometeu algum crime contra a vida.

Algumas estatísticas sobre as causas de acolhimento de jovens infratores em alguns Centros de Atendimento Socioeducativo ao Adolescente no Brasil, em 2013, mostram que 
quase $40 \%$ deles haviam sido presos por pequenos furtos. A segunda causa das detenções de adolescentes e jovens no Brasil é o tráfico, com 23,5\%. Homicídio aparece só em terceiro lugar, com menos de $10 \%$ das causas de internação (8,75\%). Latrocínio - roubo seguido de morte responde por apenas $1,95 \%$ das detenções.

As imagens e os imaginários produzidos e reproduzidos pelos meios midiáticos em relação à juventude negra e pobre

Nas sociedades contemporâneas, a maioria dos estudos realizados sobre as formas de sedução e o poder de persuasão dos meios midiáticos para conduzir a opinião das pessoas são decisivos para o comportamento social. Nesse contexto, apesar da grande propagação dos recursos da internet, principalmente das redes sociais, a televisão de canal aberto continua sendo o principal veículo de comunicação de massas, sobretudo para as classes pobres.

No Brasil, os canais de televisão aberta ainda possuem um poder de aparelho ideológico de estado (ALTHUSSER, 1985), inculcando nas pessoas uma ideia ou um ponto de vista já formado sobre determinado assunto, principalmente quando o tema é as causas da violência.

No decorrer dos anos 1990, ocorrem dois fenômenos justapostos: primeiro, a implantação do modelo de gestão do Estado, orientado pelo ultraliberalismo, como reorganização da economia capitalista; em segundo, o assustador crescimento da violência nas grandes cidades brasileiras. Simultaneamente, a esses dois fenômenos sociais, surgiram os programas de jornalismo policial sensacionalista.

Nessa conjuntura midiática, o programa policial de maior repercussão nacional foi o vespertino "Aqui Agora", ${ }^{9}$ do SBT (1991-1997). O programa tinha um formato com base em um telejornalismo dramático, emotivo, sensacionalista e muito apelativo, como já dizia seu slogan: "um jornal vibrante, uma arma do povo, que mostra na TV a vida como ela é". Tudo recheado com uma produção de índole cinematográfica, ao estilo hollywoodiano, com muita ação de rua e sua equipe de reportagens acompanhando perseguições policiais aos supostos

\footnotetext{
${ }^{9}$ Foi pioneiro, no Brasil, no uso do gerador de caracteres ao exibir manchetes bastante escandalosas sobrepostas às imagens. Seu grande foco era reportagens policiais, especialmente sobre assassinatos e crimes escandalosos. Também exibia fofocas do meio artístico e um quadro de defesa do consumidor. Alcançou altos índices de audiência e chegou a ameaçar a Rede Globo no horário.
} 
criminosos de alta periculosidade, que normalmente se refugiavam nos bairros periféricos da cidade São Paulo, principalmente menores infratores, em sua maioria cometedores de delitos comuns.

Com toda essa panaceia midiática exibida e propagada nos fins de tarde, vários apresentadores se revezavam na leitura dos textos de telejornalismo com teor justiceiro e personagem caricato, como o Homem do Sapato Branco. O "Aqui Agora", do SBT, encerrou suas atividades no ano de 1997, deixando um legado para alguns programas do mesmo gênero em outras emissoras de televisão, como "Cidade Alerta", na Rede Record, "Brasil Urgente", na Band, "Repórter Cidadão", na Rede TV, e "190 Urgente", na CNT.

Assim, nos últimos anos, impulsionados pela difusão de programas desse estilo com âncoras de renome nacional, conduzem reportagem policiais com espíritos imbuídos de judicialização da questão social, de forma totalmente distorcida, contra as classes sociais ditas de menor poderio econômico. É notória toda a influência e persuasão que esses programas possuem, principalmente na parte mais pobre da sociedade, vez que esta, formada na sua maioria por pessoas com pouca instrução, acaba tomando como verdade absoluta tudo que é veiculado, justamente por não possuírem meios e/ou condições de discordarem daquilo que é dito.

No ambiente em que se encontram os debates sobre a violência contra a juventude negra e pobre no Brasil, esses programas exercem o papel de juízes contra as denominadas "minorias" (a população negra, os povos indígenas, as mulheres, o grupo LGBT, entre outros/as atores/as sociais pertencentes aos grupos de exclusão social). De acordo com Fernanda Coelho da Silva (2008, p. 5), especialista em comunicação social, habilitada em jornalismo, nos programas de jornalismo policiais podemos perceber que,

[a] mídia, de maneira geral, usa estereótipos para tratar os temas relacionados às minorias no Brasil. Negros, movimentos sociais, mulheres e homossexuais são frequentemente vítimas de textos jornalísticos preconceituosos. Com a juventude isso não é diferente. $E$ tal situação é ainda agravada quando o jovem é negro e morador da periferia. As favelas são, muitas vezes, colocadas como espaço exclusivo de violência e os jovens negros como seus principais agentes.

Em síntese, desses programas de telejornalismo policial se absorve o abuso da transmissão direta (ao vivo), com helicópteros à disposição para ver a favela de cima, sem mostrar gente, baixa qualidade de produção jornalística e de construção textual, carregado 
de opiniões. Esse tipo de jornalismo se coloca como prestador de serviço, de defensores da moral e da honestidade, de caça aos bandidos, onde a violência é retratada de maneira bem definida: acontece nas periferias, com negros/as pobres excluídos e criminalizados pela sociedade capitalista com seu modelo de gestão social ultraliberal.

Os resultados da banalização da mídia brasileira sobre violência contra a juventude negra e pobre e suas consequências

Ao abordamos o papel dos meios midiáticos e suas implicações na produção de imagens e imaginários negativos contra a população negra, principalmente a sua juventude negra e pobre, assim como vários cientistas sociais estamos preocupados que as emissoras de televisão, rádios, jornais e revistas divulguem verdades jornalisticamente éticas e incontestáveis. Contudo, tratando-se das denominadas "minorias" (a população negra, os povos indígenas, as mulheres, o grupo LGBT, entre outros/as atores/as sociais pertencentes aos grupos de exclusão social), assistimos diuturnamente, nos temas de telejornalismo policial, a comportamentos proferidos por certo ajuizamento opinativo das notícias, com conteúdo parcial, ideologizado, manifestando reações estigmatizantes junto à população daqueles atores sociais envolvidos em alguma ocorrência policial.

No ano de 2015 houve um episódio veiculado ao vivo em rede nacional pelos programas "Cidade Alerta" e "Brasil Urgente", apresentados por Marcelo Rezende ${ }^{10}$ e José Luis Datena, respectivamente, que deixaram os telespectadores incrédulos e estarrecidos. Os dois programas mostraram um policial disparando quatro tiros contra dois jovens que já estavam rendidos após longa perseguição de moto. Imediatamente, os dois apresentadores saíram em defesa do policial. "Se ele atirou é porque o bandido estava armado. E ele fez muito bem", disse Rezende. "Não sei se os caras apontaram o revólver para o policial, não vi. Provavelmente, sim", afirmou Datena (CARVALHO, 2015).

Observamos a ratificação de algumas análises já citadas no corpo deste texto, pois a atitude dos dois apresentadores sinaliza uma orientação ideológica de conivência ao enaltecimento da violência policial, lançando mão do discurso de que "bandido bom é bandido morto". Ambos narram, com entusiasmo, as perseguições e as ações da PM pelas periferias

\footnotetext{
${ }^{10}$ Marcelo Luiz Rezende Fernandes faleceu em 2017. Era jornalista, repórter e apresentador de televisão brasileiro. Integrou programas como Linha Direta (1999), TV Record, Cidade Alerta, Domingo Espetacular, Fantástico, Globo Repórter e Jornal Nacional.
} 
da cidade de São Paulo, onde vive e convive a maioria da população negra e pobre, o que, de modo geral, acaba sendo retrato de todo o País.

Na contramão dessa conjuntura brasileira tão perversa, o Uruguai, nosso país vizinho, durante o ano de 2012, tomou algumas medidas para acabar com a violência sem a participação dos justiceiros midiáticos:

Em junho de 2012, quando o Uruguai sofria com o avanço de 70\% no número de homicídios, o presidente José Mujica anunciou um pacote de medidas para conter a criminalidade no País. Estudos e pesquisas conduzidos pela equipe do presidente concluíram que era preciso um conjunto de ações que atacasse o tráfico de drogas. O documento "Estratégia pela vida e convivência", que continha 15 medidas, foi anunciado e se tornou mundialmente conhecido porque nele o Uruguai anunciava que passaria a gerir a produção e distribuição de maconha no país. Dessa forma, o Estado assumia o posto de fornecedor da maconha aos uruguaios, era um golpe econômico nos narcotraficantes. Na outra extremidade, preocupava a ação policial. Os superpoderes dos agentes nas ruas precisavam ser combatidos, assim como a sensação de impunidade. Por isso, entre as medidas tomadas pelo governo, estava a proibição da exibição de programas policiais [similares ao "Cidade Alerta" e "Brasil Urgente"] entre 6h e 22h. A alegação é que essas "atrações televisivas" promovem atitudes ou condutas violentas e discriminatórias. Dois anos depois, em junho de 2014, o governo uruguaio anunciou que as mortes ligadas ao tráfico de drogas foram zeradas no país. (CARVALHO, 2015).

Voltando ao Brasil, no início de fevereiro de 2017 foi lançando, em Brasília, na Câmara dos Deputados, o Mapa da Violência 2016: homicídios por armas de fogo no Brasil. A publicação, desenvolvida pela Faculdade Latino-Americana de Ciências Sociais (Flacso), avalia a evolução dos homicídios por armas de fogo no Brasil, no período de 1980 a 2014, e as variantes como sexo, raça/cor e idade das vítimas, além de contar com uma série histórica que analisa os índices por estados e municípios. $O$ estudo mostra que é crescente o número de vítimas, principalmente entre jovens negros (BRASIL, 2017).

O quadro assustador dessa edição de o Mapa da Violência 2016: homicídios por armas de fogo no Brasil é que o maior número dessas mortes é registrado aos 20 anos de idade, quando os homicídios atingem a marca de 67,4 mortes por 100 mil jovens. A identificação raça/cor só começou em 2002. No período compreendido entre 2003 e 2014, o número de homicídios por arma de fogo entre a população branca diminuiu $26,1 \%$ e entre a população negra aumentou 46,9\%. Em 2003, morreram 71,7\% mais negros do que brancos e, 
em 2014, esse número saltou para 158,9\%, o que significa que morreram 2,6 vezes mais negros que brancos vitimados por armas de fogo (WAISELFISZ, 2015).

Como resultado do trabalho de pesquisa realizado por Waiselfisz (2015), o Brasil passou a se configurar mundialmente entre os 10 países que mais mata jovens no mundo, e a maior parte deles são negros/as pobres das periferias das grandes cidades. De acordo com o relatório Mapa da Violência 2016, foram mortos mais de 25 mil jovens entre 15 e 29 anos por armas de fogo no Brasil em 2014, o que representa um aumento de quase $700 \%$ em relação aos dados de 1980, quando o número de vítimas nessa faixa etária foi pouco mais de 3 mil no período (WAISELFISZ, 2016).

Em síntese, em nosso modo de entender, falta aos telejornais policiais sensacionalistas uma regulamentação mais séria por parte do Estado para que esses programas sejam mais éticos e comedidos ao tratarem de um tema tão grave e de proporção que parece incomensurável: a violência e o extermínio da juventude negra e pobre brasileira.

Qual futuro a juventude negra e pobre pode ter, imagina e o que faz para alcançá-lo?

A compreensão dos fatores que levam ao aumento do mapa da violência contra a juventude negra e pobre nesses últimos anos não é um fator restrito às relações interpessoais do dia a dia. Ao contrário, ocorre numa dimensão coletiva, de acordo com um processo social gerado por uma ideologia orgânica da sociedade capitalista ultraliberal, que serve para garantir o domínio da classe elitista branca.

A violência, conforme têm demonstrado os números do mapa da violência (WAISELFISZ, 2016), propicia um verdadeiro extermínio da juventude afro-brasileira e a profunda desigualdade existente entre negros e brancos no Brasil denuncia, por si só, que o País é racista e comete, generalizadamente, um "crime perfeito". De acordo com Kabengele Munanga, "o racismo é um crime perfeito no Brasil, porque quem o comete acha que a culpa está na própria vítima, além do mais destrói a consciência dos cidadãos brasileiros sobre a questão racial. Nesse sentido é um crime perfeito" (REVISTA FÓRUM ENTREVISTA..., 2013).

Foi no entendimento dessa dinâmica que setores mais organizados do segmento da juventude negra brasileira resolveram encarar essa realidade mais de frente e realizar o 1으 Encontro da Juventude Negra (Enjune), no Centro de Referência Afro-Brasileira de Lauro de Freitas, cidade vizinha de Salvador, Bahia, durante o mês de junho de 2007. 
Nesse evento, realizou-se uma série de debates e encaminhamentos, em forma de relatório, sobre temas específicos da juventude negra brasileira, considerando-se as diferenças e desigualdades sociais relativos à: Cultura, segurança, vulnerabilidade e risco social; Educação; Saúde; Terra e moradia; Comunicação e tecnologia; Religião do povo negro; Meio ambiente e desenvolvimento sustentável; Trabalho; Intervenção social nos espaços políticos; Reparações e ações afirmativas; Gênero e feminismo; Identidade de gênero e orientação sexual; Inclusão de pessoas com deficiência. $O$ assunto principal foi a violência, chamando a atenção para a vitimização dos jovens negros/as pelo crime organizado e uma parte considerável pela polícia (WAISELFISZ, 2004).

Apesar da alarmante violência e do genocídio sofrido pela juventude nega e pobre brasileira, esse segmento social, através de suas manifestações nos setores político, cultural e social, têm alcançado espaços de representação em vários segmentos da sociedade brasileira, apresentando-se como atores sociais capazes de estabelecer diálogos, oportunidades, conquistas e propostas políticas. Nesse sentido, combater o preconceito e racismo e mapa da violência são esforços cuja responsabilidade perpassa por todo o conjunto da sociedade civil. Assim, conforme Nilma Lino Gomes (2003, p. 220) sugere,

[a] luta contra a desigualdade racial não deve se restringir ao movimento negro, antes, deve ser uma tarefa da sociedade como um todo. A superação do racismo e da desigualdade trará resultados positivos para todos os brasileiros, de qualquer grupo étnico/racial, e não somente para a comunidade negra. O racismo é um mal que aprisiona a vítima e o opressor. A única saída contra o racismo é reverter, na prática, a situação de discriminação que os segmentos discriminados sofrem, mudando-os de posição, possibilitando-lhes a ascensão social, construindo oportunidades iguais para todos, de forma que negros e brancos tenham que conviver com dignidade em diferentes setores e instituições da sociedade e participem verdadeiramente de um processo democrático.

A partir dessa compreensão e da organização de eventos como o Ejune, busca-se apresentar um perfil afro-centrado e suprapartidário. Sua construção se dá de forma coletiva, contemplando as diversas juventudes e as particularidades de cada região, apontando para uma organização heterogênea, mas que mantém sua autonomia enquanto juventude negra. Ou seja, articulações como o Ejune são fruto da ação histórica do Movimento Social Negro, que vem construindo suas alternativas na luta antirracista e na promoção da igualdade étnico/racial de oportunidades. 


\section{Conclusões}

Nesse ensaio, refletimos sobre a violência e o genocídio contra a juventude negra e pobre brasileira, conforme apontam os dados estatísticos apresentados no Mapa da Violência 2016: homicídios por armas de fogo no Brasil, de autoria do sociólogo Julio Jacobo Waiselfisz, que nos mostra imagens e imaginários da sociedade de uma crise capitalista que continua rondando nosso cotidiano desde quando o neoliberalismo reabriu, no início 1992, as portas do "capitalismo selvagem"11 (denominação que o sociólogo Florestan Fernandes havia atribuído, de forma tão brilhante, ao capitalismo brasileiro no ano de 1972) em nosso País.

Em nossa opinião, a sociedade precisa aceitar, de um modo geral, que ainda não conseguimos romper com os escombros da herança da sociedade escravocrata mesmo depois de mais de 130 anos de sua extinção. Nesse sentido, precisamente, esse pensamento persiste no imaginário ideológico de uma elite branca e racista, que atua conscientemente para diminuir o valor de vidas negras e pobres apenas como corpos caídos ao chão, ou relegados à escuridão dos sistemas prisionais denominados 'centros socioeducativos', que não possuem políticas públicas qualificadas e suficientes para propiciar uma real ressocialização da juventude negra e pobre brasileira.

No que diz respeito ao quadro lamentável do levantamento sistemático da evolução dos homicídios por armas de fogo no Brasil no período de 1980 a 2014, realizado pelo sociólogo Júlio Jacobo Waiselfisz, estimativas indicam que maioria das incidências de fatores como o sexo, a raça/cor e a idade das vítimas dessa mortalidade são expressivamente contra a raça negra. Desse modo, a juventude negra procura, a duras penas, formas organizativas para reverter esse quadro.

É notório que algumas iniciativas por parte do Estado já foram tomadas, como a criação, no ano de 2004, da Secretaria Nacional de Juventude (SNJ), sob a coordenação da Secretaria Geral da Presidência da República, articulada para fazer um diagnóstico da juventude brasileira e dos programas do governo federal destinados a esse público. A tarefa

\footnotetext{
${ }^{11}$ A expressão 'capitalismo selvagem' é um termo criado originalmente pela literatura marxista, para se referir à fase do capitalismo na época da Primeira Revolução Industrial (cerca de fins do século XVIII). Naquela época, especialmente na Grã-Bretanha, camponeses empobrecidos vindos de um meio rural superpovoado e estagnado não tinham outra alternativa senão trabalhar nas nascentes indústrias da época, criadas a partir das inovações tecnológicas que pipocavam a todo o momento, em especial o tear mecânico ou, ainda, o motor a vapor. Obviamente, nesse cenário cheio de inovações, não havia nenhum regulamento ou disposição prevendo como se dariam as relações entre os donos de fábricas e seus empregados.
} 
principal do órgão deveria ser coordenar, integrar e articular políticas públicas para a juventude, além de promover programas de cooperação com organismos nacionais e internacionais, públicos e privados, voltados para as políticas juvenis. Contudo, os estudos das reais condições em que se encontram a juventude negra e pobre brasileira demonstram que a SNJ não tem sido muito competente para solucionar os problemas generalizados que o afligem, principalmente a violência e o genocídio.

Portanto, concluímos que a luta contra o racismo, ao contrário do que muitos podem pensar, não é uma tarefa apenas dos setores organizados do Movimento Social Negro, e sim uma responsabilidade e dever de toda a sociedade brasileira.

\section{REFERÊNCIA BIBLIOGRÁFICAS}

ALTHUSSER, Louis. Aparelhos ideológicos de Estado: nota sobre os aparelhos ideológicos de Estado (AE). 2. ed. Rio de Janeiro: Editora Graal, 1985.

BRASIL. Ministério da Mulher, da Família e dos Direitos Humanos. Mapa da Violência 2016 é lançado em Brasília. 16 de fevereiro de 2017. Disponível em: https://www.gov.br/mdh/ptbr/noticias_seppir/noticias/2017/02-fevereiro/mapa-da-violencia-2016-e-lancado-em-brasilia-2.

Acesso em: 23 dez. 2020.

CARVALHO, I. Antes de zerar morte por tráfico, Uruguai proibiu programas policiais. Carta Maior, o Portal da Esquerda, 14 de julho de 2015. Disponível em: https://www.cartamaior.com.br/?/Editoria/Midia/Antes-de-zerar-morte-por-trafico-Uruguai-proibiuprogramas-policiais\%25250A/12/33987. Acesso em: 23 dez. 2020.

CERQUEIRA, D. et al. (orgs.). Atlas da violência 2016. Brasília: Ipea: Fórum Brasileiro de Segurança Pública, 2016. (Nota Técnica; 17).

CUNHA, E. da. Os Sertões: Companhia de Canudos. Edição, prefácio, cronologia, notas e índices de Leopoldo M. Bernucci. São Paulo: Ateliê Editorial: Imprensa Oficial do Estado: Arquivo do Estado, 2001.

FERNANDES, F. A integração do negro na sociedade de classes. 3. ed. São Paulo: Ática, 1978.

GALTON, F. Hereditary talent and character. Macmillan's Magazine, v. 12, p. 157-66, p. 318-27, 1865.

GOMES, N. L. Ações afirmativas: dois projetos voltados para a juventude negra. In: GONÇALVES E SILVA, P. B.; SILVÉRIO, V. R. (orgs.). Educação e ações afirmativas: entre a injustiça simbólica e a injustiça econômica. Brasília: Ipea, 2003. p. 217-244.

GONZALÉZ, L. A juventude negra brasileira e a questão do desemprego. Brasília: Ipea, 28 de abril de 1979.

HASENBALG, C. Discriminação e desigualdades raciais no Brasil. 2. ed. Belo Horizonte: Ed. UFMG; Rio de Janeiro: IUPERJ, 2005.

HENRIQUES, R. Para acabar com a pobreza. República, São Paulo, n. 51, jan. 2001. 
HOFBAUER, A. O conceito de 'raça' e o ideário do 'branqueamento' no século XIX - Bases ideológicas do racismo brasileiro. Teoria e pesquisa (UFSCar), São Carlos, n. 42-43, p. 63-110, 2003.

IBGE - Instituto Brasileiro de Geografia e Estatística. Desigualdades Sociais por Cor ou Raça no Brasil. Disponível em: https://www.ibge.gov.br/estatisticas/sociais/populacao/25844-desigualdades-sociaispor-cor-ou-raca.html?=\&t=sobre. Acesso em: 23 dez. 2020.

JACCOUD, L. et al. Entre o racismo e a desigualdade: da Constituição à promoção de uma política de igualdade racial (1988-2008). In: JACCOUD, L. (org.). A construção de uma política de promoção da igualdade racial: uma análise dos últimos 20 anos. Brasília: Ipea, 2009. p. 19-92.

MUNANGA, K. Políticas de ação afirmativa em benefício da população negra no Brasil: um ponto de vista em defesa de cotas. Sociedade e cultura, v. 4, n. 2, p. 31-43, 2001.

MUNANGA, K. Negritude: usos e sentidos. 2. ed. São Paulo: Ática, 1986.

PAIXÃO, M. et al. (orgs.). Relatório anual das desigualdades raciais no Brasil; 2009-2010. Constituição Cidadã, seguridade social e seus efeitos sobre as assimetrias de cor ou raça. Rio de Janeiro: Garamond, 2010.

REVISTA FÓRUM ENTREVISTA antropólogo Kabengele Munanga (USP). Hum historiador, 10 de novembro de 2013. Disponível em: https://umhistoriador.wordpress.com/2013/11/10/revista-forumentrevista-antropologo-kabengele-munanga-usp/. Acesso em: 2 dez. 2020.

RIBEIRO, C. A. C. Classe, raça e mobilidade social no Brasil. Dados - Revista de Ciências Sociais, Rio de Janeiro, v. 494, 2006.

ROMERO, S. O Alemanismo no Sul do Brasil. Seus perigos e meios de os conjurar. Rio de Janeiro: Heitor Ribeiro, 1906.

SANSONE, L.; PINHO, O. A. (orgs.). Raça: novas perspectivas antropológicas. 2. ed. rev. Salvador: ABA: EDUFBA, 2008.

SILVA, F. C. A juventude na mídia brasileira: estereótipos e exclusão. Revista Anagrama - Revista Interdisciplinar da Graduação, ano 1, edição 4, p. 1-10, jun./ago. 2008.

SCHWARCZ, L. M. O espetáculo das raças. Cientistas, instituições e questão racial no Brasil, 1870-1930. São Paulo: Companhia das Letras, 1993.

VIANNA, O. Populações meridionais do Brasil. Niterói, RJ: Ed. da UFF, 1987.

WAISELFISZ, J. J. Mapa da violência: os jovens do Brasil. Brasília, DF: Unesco, 2004. v. 4.

WAISELFISZ, J. J. Mapa da Violência 2016 - Homicídios por armas de fogo no Brasil. Rio de Janeiro: Flacso/Cebela, 2016.2 p. 54-60. Disponível em: http://flacso.org.br/files/2016/08/Mapa2016_armas_web-1.pdf. Consulta em: 20/11/2020. 